\title{
A MIGRAÇÃo PARA MINAS GERAIS: O RETORNO DE MINEIROS E A IMIGRAÇÃO PAULISTA NAS ÚLTIMAS DÉCADAS*
}

Carlos Lobo ${ }^{* *}$

Ralfo Matos ${ }^{* * *}$

\section{RESUMO}

Minas Gerais tem historicamente perdido população para o estado de São Paulo há pelo menos 100 anos. Os fluxos migratórios entre essas Unidades da Federação expressavam trocas populacionais muito desiguais, amplamente favoráveis a São Paulo, sobretudo no período 19401980. Sucessivas dificuldades econômicas que Minas enfrentou certamente explicam seu perfil emigratório tão persistente. Entretanto, mudanças nas trocas entre São Paulo e Minas já podiam ser observadas nos dados do Censo de 1991, quando mostrava o declínio do nível de perdas do estado em relação a São Paulo. Os dados do Censo de 2010 não só confirmam essa tendência, como indicam um novo cenário: Minas Gerais passa a receber contingentes crescentes procedentes de São Paulo. A expansão da área de influência de São Paulo no Sudeste pode estar criando novas centralidades regionais, que vêm absorvendo parte dos efeitos do processo de desconcentração econômica e demográfica da metrópole paulista. Assim sendo, os dados devem, em alguma medida, expressar essa evidência de dispersão. Regiões como as do Sul de Minas, Triângulo e Mata, a princípio, seriam as áreas ganhadoras de migrantes, seja de mineiros retornados, ou mesmo de paulistas.

PALAVRAS CHAVES: Migração; População; Minas Gerais; São Paulo.

\footnotetext{
* Trabalho apresentado no X Encontro Nacional sobre Migração, realizado em Natal/RN - Brasil, de 16 a 18 de outubro de 2017.

** Doutor em Geografia. Professor dos Programas de Pós-Graduação em Geografia e em Análise e Modelagem de Sistemas Ambientais, ambos do IGC/UFMG.

**** Doutor em Demografia. Professor do Programa de Pós-Graduação em Geografia do IGC/UFMG.
} 


\section{INTRODUÇÃO}

Por mais de um século Minas Gerais foi um dos maiores perdedores de população do Brasil. O dinamismo dos principais centros do Sudeste, ou nas fronteiras agrícolas em expansão, associado às recorrentes dificuldades econômicas internas, pode ser visto como importante fator na evolução da emigração mineira ao longo do século XX. Talvez, para além das desigualdades territoriais existentes, a condição emigratória de Minas Gerais não tivesse se revelado com tanta intensidade sem a grande acumulação de população que o estado experimentou por muito tempo, especialmente ao longo do século XIX. Ainda no início do século XX, Minas abrigava perto de $1 / 5$ da população brasileira e seu crescimento vegetativo era relativamente alto. $\mathrm{O}$ fator demográfico, portanto, auxilia na explicação dos impressionantes saldos migratórios negativos que Minas Gerais acumulou em grande parte do século XX. Com tão expressivos estoques populacionais e diante da perda do dinamismo da economia mineira em fins do século XIX não seria surpresa a liberação de crescentes contingentes populacionais. Com as primeiras décadas do século XX e a intensificação do processo de industrialização e urbanização concentrado, aumentaram as saídas de migrantes rumo ao estado São Paulo, e um pouco depois, rumo às fronteiras agrícolas no norte do Paraná e do Centro-Oeste (Coelho, et. al., 1982). Se de um lado a pujança econômica paulista operava como um fator de atração populacional, de outro a decadência de determinadas regiões mineiras mostrava-se patente, sobretudo nas áreas rurais.

Em meados do século passado o estado de São Paulo, principalmente em sua região metropolitana, consolida-se como a principal área receptora de emigrantes de Minas Gerais. Na década de 1970, ponto culminante dos grandes saldos migratórios brasileiros como mostra RIGOTTI (1999), São Paulo apresenta o maior saldo migratório intercensitário da história brasileira, exibindo um ganho de mais de 3,5 milhões de pessoas (somado o efeito indireto). Nesse decênio, Minas Gerais já apresentava um arrefecimento de suas perdas populacionais, que se refletia na redução do saldo negativo (de mais de 1,4 milhão de pessoas, contra 1,6 milhão na década anterior). Essa tendência de redução se confirmou com os dados referentes à década de 1980, quando o saldo migratório negativo atingiu valores próximos a 800 mil pessoas. Nesse momento, a economia brasileira passava por uma situação de crise, com escassez de postos no mercado de trabalho dos grandes centros urbano. Do ponto de vista demográfico, a mortalidade e a fecundidade experimentavam sucessivos declínios. Com isso, os grandes volumes de população excedente tendiam a diminuir, em meio a mudanças na própria dinâmica migratória (MATOS, 1995). 
Dados demográficos mais recentes permitem identificar mudanças no volume e nos padrões nas trocas populacionais da migração em Minas Gerais, especialmente em relação aos fluxos que envolvem o estado de São Paulo. O Censo de 1991 mostrava arrefecimento em seu ritmo de crescimento e, pela primeira vez, a região metropolitana de São Paulo com saldo migratório negativo de 274.000 pessoas. A capital paulista teria sido a principal responsável pela perda líquida de população na década de 1980, com saldo negativo de 750.000 pessoas (BAENINGER, 1997). Essa alteração no balanço migratório paulista foi resultado direto da queda na imigração e do aumento da emigração, particularmente sob a forma de emigrantes que retornavam aos seus estados de origem. Na década seguinte, os dados de migração de data fixa, referentes ao período de 1995-2000, confirmam as tendências anteriores, mostrando um fato inédito: a inversão da posição de Minas em relação a São Paulo no que diz respeito às trocas de população. Os migrantes procedentes de São Paulo eram superiores aos que os saíram de Minas.

No interior dessa mudança, é provável que novas centralidades estejam se afirmando em Minas Gerais, o que explicaria parte da reversão nos padrões de trocas, já que mudanças econômicas em curso podem ampliar o grau de proximidade e interação entre regiões que, histórica e geograficamente, sempre estiveram interligadas a São Paulo, a exemplo do Sul de Minas e Triângulo Mineiro, ou mesmo Campo das Vertentes, Oeste de Minas e Noroeste. De outro lado, as trocas entre as regiões menos próximas, como a própria Região Metropolitana de Belo Horizonte, também podem sugerir facetas menos óbvias do processo migratório, de acordo com o tipo de migrante em questão. Nesse sentido, algumas regiões mineiras permanecem perdendo população para o estado de São Paulo, tais como o arco nordeste/norte (Doce, Mucuri, Jequitinhonha e Norte), mesmo que ainda recebam um número não desprezível de migrantes de retorno.

Diante desse novo cenário migratório, esse artigo se propõe a analisar as trocas de migração que envolvem em Minas Gerais nas últimas décadas, especialmente nas trocas que envolvem o estado de São Paulo, discriminados conforme a Unidade da Federação (UF) de Nascimento (mineiros e paulistas). Para tanto, foram utilizadas os microdados amostrais dos Censos Demográficos de 1980, 1991, 2000 e 2010, utilizando-se da chamada migração de última etapa, cujos migrantes foram identificados pela combinação entre a UF de residência na data de referência de cada recenseamento, a de última residência e de nascimento (essa última permitiu discriminar os imigrantes como mineiros ou paulistas). 


\section{AS MIGRAÇOES E A DISTRIBUIÇÃO ESPACIAL DA POPULAÇÃO: ASPECTOS TEÓRIOS E CONCEITUAIS}

A análise da estrutura e distribuição espacial da população não é nova. Ravenstein (1980), por exemplo, ao final do século XIX e início do XX, já apontava que há expressivas relações entre as atividades econômicas e os deslocamentos espaciais da população, sobretudo no que diz respeito à distância, aos movimentos por etapas, à configuração das correntes e contracorrentes, à predominância da migração feminina e, também, ao fato de que as migrações tendiam a gerar movimentos sucessivos a partir de áreas próximas a um centro industrial ou comercial. As grandes cidades "proporcionam facilidades tão extraordinárias à divisão e à combinação do trabalho, ao exercício de todas as artes e à prática de todas as profissões que, a cada ano, um número maior de pessoas nelas possa habitar" (RAVENSTEIN, 1980, p.26). Para esse mesmo autor, há outros aspectos que devem ser considerados, dado o efeito indutor na migração, tais como: as facilidades educacionais, a salubridade do clima ou a carestia de vida. Ao rever as teses de Ravestein, Lee (1980) introduz algumas informações adicionais acerca dos movimentos internos nas sociedades de capitalismo tardio. Em sua análise, Lee (1980) que a decisão de migrar está vinculada a uma decisão racional (embora não exclusiva), envolvendo os chamados fatores positivos e negativos nas áreas de origem e destino. Torna-se natural, na perspectiva oferecida por esse autor, que pessoas distintas sejam afetadas de maneira diferente por uma série de obstáculos ou incentivos à possibilidade de migrar. Embora não exclua literalmente a perspectiva individual, Singer (1973) considera a migração um reflexo direto da estrutura e dos mecanismos de desenvolvimento do sistema capitalista, cujo motor principal é o acirramento das desigualdades regionais. Para esse autor,

É claro que qualquer processo de industrialização implica uma ampla transferência de atividades (e, portanto, de pessoas) do campo às cidades. Mas, nos moldes capitalistas, tal transferência tende a se dar a favor de apenas algumas regiões em cada país, esvaziando as demais. Tais desequilíbrios regionais são bem conhecidos e se agravam na medida em que as decisões locacionais são tomadas tendo por critério apenas a perspectiva da empresa privada (SINGER, 1973, p.222).

A contribuição de Singer (1973), especialmente no que se relaciona às reflexões sobre a migração, está na identificação de como os chamados fatores da atração refletem a necessidade de mão de obra reflexo do crescimento da produção industrial e da expansão do setor de serviços urbanos. Os fatores de expulsão, por sua, vez, podem ser divididos em fatores de mudança, decorrentes da penetração do capitalismo no campo e da adoção de um sistema poupador de mão de obra, e em fatores de estagnação, ligados à pressão demográfica exercida 
sobre a terra. As regiões de mudança perdem população, mas a produtividade aumenta, o que permite, pelo menos em princípio, uma melhora nas condições de vida locais. Já as áreas de estagnação apresentam deterioração da qualidade de vida, funcionando às vezes como "viveiros de mão de obra" para os latifundiários e para as grandes empresas agrícolas (SINGER, 1973).

Na mesma abordagem estruturalista, há ainda alguns autores que consideram a migração como fluxo profundamente ligado à criação, expansão e articulação dos mercados de trabalho. Se o desenvolvimento é desigual no âmbito do capitalismo, a população se distribui seguindo a mesma lógica de intensificação dos espaços econômicos, formando grandes reservatórios de mão de obra. Afora o mérito de tais formulações, a abordagem estruturalista não consegue abarcar toda a multiplicidade das causas mais dinâmicas e específicas da migração, tais como, as vantagens comparativas e as potencialidades externas que têm transformado os espaços de destino. Para Matos (1995) há pouco esforço na análise da migração de origem urbana, além de quase sempre não haver sequer menção à migração de retorno.

Adicionalmente, não existe investimento substantivo na compreensão dos efeitos positivos que a migração pode gerar na dinamização das regiões de destino, tanto no que diz respeito à oferta de mão de obra qualificada, como a certas possibilidades de novos investimentos e de intercâmbio técnico, por exemplo. A análise da migração dá visibilidade a processos sociais mais amplos, não se limitando a ser um simples indicador de concentração ou dispersão das atividades econômicas. Permite, inclusive, identificar o perfil de desenvolvimento rural e urbano, as formas institucionais e sociais de difusão de informações e inovações, a inserção tardia ou avançada na transição demográfica e os graus de desigualdade regional quando discutem sobre o fim do padrão concentrador das atividades. Para Matos (2003), devese dar visibilidade às alterações recentes no padrão migratório brasileiro, o qual vem se caracterizando pela secundarização dos fluxos oriundos do campo em direção às cidades e pela complexificação da rede urbana, sinais evidentes do aumento de certas externalidades positivas na periferia e dos novos fluxos migratórios que já se dirigem às cidades médias.

Considerando que a organização dos elementos do espaço deve ser encarada como o resultado histórico da atuação dos atores políticos, sociais e econômicos, os fluxos de informação, capitais e pessoas, por exemplo, permitem e alimentam o dinamismo das formas e funções dos elementos que compõem e caracterizam o espaço. De acordo com Santos (1997), a fluidez é uma das mais importantes características do mundo atual que é, ao mesmo tempo, causa, condição e resultado de sua própria necessidade. As migrações internas são, por essência, manifestações desses fluxos que se materializam no espaço. Tratam-se de contingentes de 
pessoas que se deslocam no espaço, reflexo não exclusivo de uma realidade social e/ou condição econômica momentânea, mas, ainda, causas e consequências de outros fluxos. Envolvem, inclusive investimentos, tecnologias e experiências profissionais, que podem traduzir-se em expressivos incrementos positivos nas áreas de origem. Avaliar essa fluidez no âmbito regional é um desafio proposto nesse trabalho. As migrações internas são, por essência, manifestações desses fluxos que se materializam no espaço. Tratam-se de contingentes de pessoas que se deslocam no espaço, reflexo não exclusivo de uma realidade social e/ou condição econômica momentânea, mas, ainda, causas e consequências de outros fluxos. Envolvem, inclusive investimentos, tecnologias e experiências profissionais, que podem traduzir-se em expressivos incrementos positivos nas áreas de origem. Avaliar essa fluidez no âmbito regional é um desafia proposto nesse trabalho (LOBO, 2016).

\section{A MIGRAÇÃO EM MINAS GERAIS: ALGUMAS EVIDÊNCIAS EMPÍRICAS ATUAIS}

Os fluxos migratórios de Minas Gerais, expostos na Tabela 1, que cobrem o período intercensitário 1980-2010, sempre foram muitos relevantes com as regiões Sudeste e Nordeste. Em 1980 eram 308.752 imigrantes (58,1\% do total da imigração) e 426.578 em 2010 (58,5\%) provenientes do Sudeste, enquanto o Nordeste enviou 68.247 imigrantes para Minas (12,8\%) e 157.673 pessoas em 2010 (21,6\% dos imigrantes). Nesses 30 anos a importância relativa dos imigrantes procedentes do Sudeste manteve-se a mesma, enquanto a do Nordeste aumentou significativamente. Nas trocas com o Centro Oeste, outra região vizinha de Minas houve uma inversão: enquanto em 1980 os procedentes dessa região (incluindo o DF) alcançavam 18,1\% do total, em 2010 essa proporção reduziu-se 12,2\%. Esses dados mostram que as tendências migratórias vêm se alterando inter regionalmente, algumas apontando maior retenção da população (CO) outras mantiveram sua característica expulsora, como o Nordeste, enquanto o Sudeste, a despeito de alto volume populacional, expõe a grande relevância dos fluxos originários do estado de São Paulo.

Já entre os fluxos de emigração, as mesmas regiões também se destacam. Com o Sudeste, região na qual Minas Gerais se inclui, em 1980, ela remetia para o resto da região 809.239 pessoas (71,1\% do total dos emigrantes de Minas) enquanto 30 anos depois ela enviava bem menos: 604.716 o que equivalia a 68\% da emigração do Estado. Com o Nordeste em 1980 Minas enviava apenas 4,7\% do total dos emigrados e 7,9\% em 2010 (evidenciando um aumento relativo de fluxos do Estado em direção ao Nordeste). Com o Centro Oeste a emigração continuou proporcionalmente bastante relevante, pois em 1980 cerca de 14,7\% das saídas de 
Minas foram para essa região e em 2010 essa proporção aumentou atingindo 16,2\% da emigração de Minas Gerais. Os números do Sudeste novamente são muito elevados por causa da migração Minas-São Paulo, como mostrava a tradição de mineiros buscarem São Paulo em busca de emprego e melhoria das condições de vida.

Os resultados permitem afirmar que Minas Gerais teve sensível mudança no saldo migratório quando avaliadas as últimas décadas. De um saldo negativo superior a $-606.888 \mathrm{em}$ 1980 passou para -87.617 pessoas em 2010, sendo que em 2000 o saldo foi positivo. Essa queda nas perdas via migração foi decorrente de duas tendências simultâneas: redução da emigração (de 1.138.497 em 1980 para 816.368 em 2010) e aumento da imigração (de 531.609 em 1980 para 728.751em 2010). Boa parte nessa mudança deve-se a redução do peso e da emigração para de São Paulo. Como pode ser observado na figura 1, desde 1980 as perdas migratórias nas trocas com esse estado têm sido cada vez menores. Trata-se de uma mudança decorrente, em boa medida, da sensível queda na emigração de Minas Gerais para São Paulo, além de crescimento da imigração (pelo menos até o ano 2000).

A análise da figura 2, que discrimina a UF de nascimento dos imigrantes procedentes de São Paulo, demonstra o crescimento da imigração de paulistas daqueles procedentes desse estado. Em 2010, os imigrantes vindos do estado vizinho já se tornaram maioria, sendo mais numerosos, inclusive, que os mineiros que retornaram a UF de nascimento. Nos dois últimos recenseamentos, o número de paulistas vindos de São Paulo foi superior a 150 mil (em 2000 esse contingente chegou a 167.112). A figura 3 representa a distribuição espacial desses dois grupos de imigrantes no ano 2000. No caso dos mineiros, além daqueles que se dirigiram a capital das alterosas, chama atenção a elevada abrangência espacial, incluindo municípios do norte e nordeste, além das regiões mais próximas a São Paulo, como o Sul de Minas e Triângulo Mineiro.

Quanto aos paulistas, destaca a forte concentração nas regiões Triângulo Mineiro e Sul de Minas, embora não seja desprezível a ida para a meso Metropolitana de Belo Horizonte. Os quatro municípios que receberam mais de 5 mil paulistas em 2010 foram: Belo Horizonte, Uberlândia, Uberaba e Poços de Caldas, nessa ordem. Com um contingente entre mil e 5 mil migrantes paulistas foram 22 municípios, especialmente no Sul de Minas (com um total de 13 casos). 
Tabela 1: Número e percentual de imigrantes e emigrantes em/de Minas Gerais, conforme UF de origem, 1980, 1991,2000 e 2010 (migração de última etapa)

\begin{tabular}{|c|c|c|c|c|c|c|c|c|c|c|c|c|c|c|c|c|}
\hline \multirow{3}{*}{ UF/Macrorregião } & \multicolumn{4}{|c|}{1980} & \multicolumn{4}{|c|}{1991} & \multicolumn{4}{|c|}{2000} & \multicolumn{4}{|c|}{2010} \\
\hline & \multicolumn{2}{|c|}{ Imigrantes } & \multicolumn{2}{|c|}{ Emigrantes } & \multicolumn{2}{|c|}{ Imigrantes } & \multicolumn{2}{|c|}{ Emigrantes } & \multicolumn{2}{|c|}{ Imigrantes } & \multicolumn{2}{|c|}{ Emigrantes } & \multicolumn{2}{|c|}{ Imigrantes } & \multicolumn{2}{|c|}{ Emigrantes } \\
\hline & $\mathbf{N}^{\circ}$ & $\%$ & $\mathbf{N}^{\circ} \mid$ & $\%$ & $\mathbf{N}^{0}$ & $\%$ & $\mathbf{N}^{0}$ & $\%$ & $\mathbf{N}^{0}$ & $\%$ & $\mathbf{N}^{\circ}$ & $\%$ & $\mathbf{N}^{0}$ & $\%$ & $\mathbf{N}^{\circ} \mid$ & $\%$ \\
\hline Rondônia & 1.047 & 0,20 & 18.435 & 1,62 & 10.473 & 1,59 & 31.653 & 3,78 & 9.884 & 1,11 & 14.825 & 1,67 & 3.675 & 0,50 & 9.434 & 1,16 \\
\hline Acre & 171 & 0,03 & 934 & 0,08 & 751 & 0,11 & 925 & 0,11 & 738 & 0,08 & 837 & 0,09 & 637 & 0,09 & 1.040 & 0,13 \\
\hline Amazonas & 969 & 0,18 & 1.839 & 0,16 & 3.422 & 0,52 & 1.912 & 0,23 & 3.277 & 0,37 & 1.874 & 0,21 & 2.184 & 0,30 & 2.946 & 0,36 \\
\hline Roraima & 98 & 0,02 & 160 & 0,01 & 315 & 0,05 & 459 & 0,05 & 766 & 0,09 & 679 & 0,08 & 689 & 0,09 & 673 & 0,08 \\
\hline Pará & 3.577 & 0,67 & 22.605 & 1,99 & 9.317 & 1,42 & 15.093 & 1,80 & 13.324 & 1,49 & 10.498 & 1,18 & 11.106 & 1,52 & 12.577 & 1,54 \\
\hline Amapá & 321 & 0,06 & 91 & 0,01 & 309 & 0,05 & 505 & 0,06 & 375 & 0,04 & 523 & 0,06 & 781 & 0,11 & 838 & 0,10 \\
\hline Tocantins & 22 & 0,00 & 19.321 & 1,70 & 2.411 & 0,37 & 5.486 & 0,65 & 5.244 & 0,59 & 7.390 & 0,83 & 5.230 & 0,72 & 7.100 & 0,87 \\
\hline Norte & 6.205 & 1,17 & 63.385 & 5,57 & 26.997 & 4,10 & 56.032 & 6,69 & 33.610 & 3,76 & 36.627 & 4,13 & 24.302 & 3,33 & 34.607 & 4,24 \\
\hline Maranhão & 2.511 & 0,47 & 5.388 & 0,47 & 4.555 & 0,69 & 3.799 & 0,45 & 8.878 & 0,99 & 4.097 & 0,46 & 15.692 & 2,15 & 5.446 & 0,67 \\
\hline Piauí & 1.349 & 0,25 & 597 & 0,05 & 1.748 & 0,27 & 1.273 & 0,15 & 3.970 & 0,44 & 1.878 & 0,21 & 6.486 & 0,89 & 2.455 & 0,30 \\
\hline Ceará & 4.839 & 0,91 & 1.881 & 0,17 & 7.981 & 1,21 & 3.523 & 0,42 & 11.264 & 1,26 & 6.753 & 0,76 & 16.149 & 2,22 & 5.753 & 0,70 \\
\hline Rio Grande do Norte & 3.437 & 0,65 & 1.621 & 0,14 & 3.561 & 0,54 & 2.446 & 0,29 & 6.123 & 0,69 & 3.454 & 0,39 & 4.756 & 0,65 & 3.307 & 0,41 \\
\hline Paraíba & 2.931 & 0,55 & 1.163 & 0,10 & 3.262 & 0,50 & 1.702 & 0,20 & 4.994 & 0,56 & 2.032 & 0,23 & 6.094 & 0,84 & 2.739 & 0,34 \\
\hline Pernambuco & 5.322 & 1,00 & 2.677 & 0,24 & 6.421 & 0,98 & 4.316 & 0,51 & 10.400 & 1,16 & 5.195 & 0,59 & 13.866 & 1,90 & 6.224 & 0,76 \\
\hline Alagoas & 1.382 & 0,26 & 594 & 0,05 & 1.902 & 0,29 & 1.125 & 0,13 & 6.130 & 0,69 & 1.951 & 0,22 & 21.973 & 3,02 & 2.876 & 0,35 \\
\hline Sergipe & 924 & 0,17 & 686 & 0,06 & 1.766 & 0,27 & 1.331 & 0,16 & 2.262 & 0,25 & 1.524 & 0,17 & 2.956 & 0,41 & 2.159 & 0,26 \\
\hline Bahia & 45.552 & 8,57 & 38.398 & 3,37 & 43.973 & 6,68 & 36.573 & 4,36 & 77.175 & 8,64 & 43.129 & 4,86 & 69.701 & 9,56 & 45.300 & 5,55 \\
\hline Nordeste & 68.247 & 12,84 & 53.005 & 4,66 & 75.170 & 11,43 & 56.088 & 6,69 & 131.196 & 14,68 & 70.013 & 7,89 & 157.673 & 21,64 & 76.258 & 9,34 \\
\hline Espírito Santo & 36.848 & 6,93 & 81.141 & 7,13 & 48.618 & 7,39 & 86.263 & 10,29 & 62.586 & 7,00 & 88.792 & 10,00 & 44.174 & 6,06 & 78.035 & 9,56 \\
\hline Rio de Janeiro & 77.535 & 14,58 & 160.551 & 14,10 & 102.836 & 15,63 & 89.489 & 10,68 & 116.863 & 13,08 & 104.335 & 11,75 & 90.299 & 12,39 & 99.833 & 12,23 \\
\hline São Paulo & 194.369 & 36,56 & 567.547 & 49,85 & 269.298 & 40,93 & 385.895 & 46,05 & 386.368 & 43,23 & 411.590 & 46,36 & 292.106 & 40,08 & 337.194 & 41,30 \\
\hline Sudeste & 308.752 & 58,08 & 809.239 & 71,08 & 420.753 & 63,95 & 561.647 & 67,02 & 565.817 & 63,31 & 604.716 & 68,12 & 426.578 & 58,54 & 515.061 & 63,09 \\
\hline Paraná & 45.309 & 8,52 & 27.761 & 2,44 & 28.030 & 4,26 & 18.678 & 2,23 & 28.946 & 3,24 & 21.484 & 2,42 & 19.109 & 2,62 & 23.721 & 2,91 \\
\hline Santa Catarina & 1.776 & 0,33 & 2.541 & 0,22 & 2.810 & 0,43 & 3.532 & 0,42 & 4.703 & 0,53 & 5.367 & 0,60 & 5.805 & 0,80 & 8.596 & 1,05 \\
\hline Rio Grande do Sul & 4.992 & 0,94 & 3.775 & 0,33 & 6.355 & 0,97 & 4.097 & 0,49 & 6.836 & 0,76 & 5.387 & 0,61 & 6.633 & 0,91 & 7.210 & 0,88 \\
\hline Sul & 52.077 & 9,80 & 34.077 & 2,99 & 37.196 & 5,65 & 26.307 & 3,14 & 40.485 & 4,53 & 32.238 & 3,63 & 31.548 & 4,33 & 39.528 & 4,84 \\
\hline Mato Grosso do Sul & 4.166 & 0,78 & 7.758 & 0,68 & 4.989 & 0,76 & 8.129 & 0,97 & 7.098 & 0,79 & 7.039 & 0,79 & 6.287 & 0,86 & 9.171 & 1,12 \\
\hline Mato Grosso & 5.450 & 1,03 & 27.544 & 2,42 & 9.994 & 1,52 & 19.528 & 2,33 & 12.997 & 1,45 & 16.181 & 1,82 & 7.912 & 1,09 & 12.658 & 1,55 \\
\hline Goiás & 68.063 & 12,80 & 65.941 & 5,79 & 54.252 & 8,25 & 61.286 & 7,31 & 67.985 & 7,61 & 67.968 & 7,66 & 44.188 & 6,06 & 72.186 & 8,84 \\
\hline Centro-Oeste & 77.679 & 14,61 & 101.243 & 8,89 & 69.235 & 10,52 & 88.943 & 10,61 & 88.081 & 9,86 & 91.188 & 10,27 & 58.387 & 8,01 & 94.014 & 11,52 \\
\hline Distríto Federal & 18.649 & 3,51 & 77.548 & 6,81 & 28.583 & 4,34 & 49.048 & 5,85 & 34.494 & 3,86 & 52.951 & 5,96 & 30.263 & 4,15 & 56.899 & 6,97 \\
\hline otal & 531.609 & 100,00 & 1.138 .497 & 100,00 & 657.933 & 100,00 & 838.066 & 100,00 & 893.683 & 100,00 & $\mathbf{8 8 7 . 7 3 3}$ & 100,00 & 728.751 & 100,00 & 816.368 & 100,00 \\
\hline
\end{tabular}

Fonte: IBGE, Censos Demográficos de 1980, 1991, 2000 e 2010 (dados da amostra). 


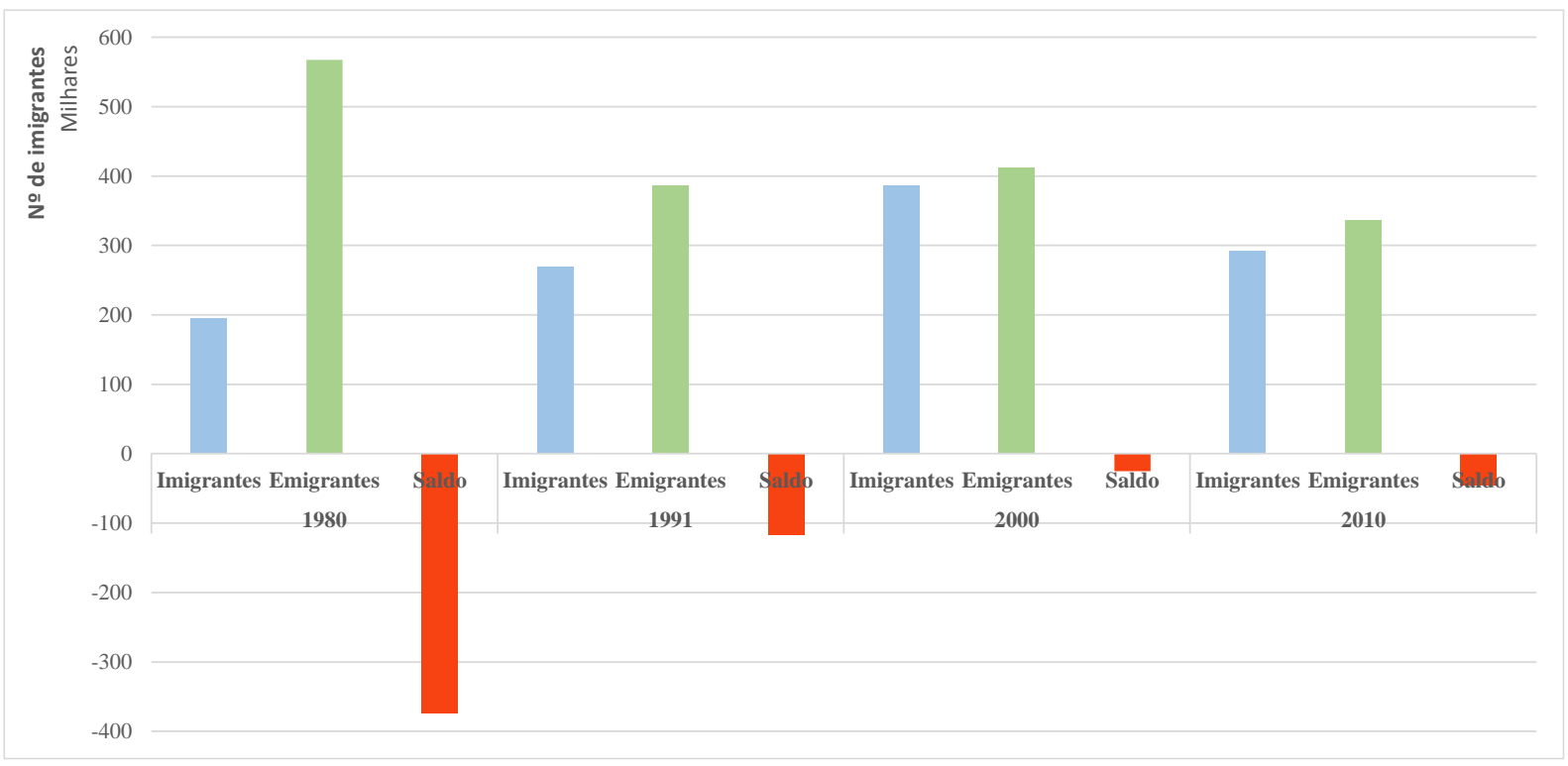

Figura 1: Número de imigrantes, emigrantes e saldo migratório em Minas Gerais procedente de São Paulo (migração de última etapa) 1980, 1991, 2000 e 2010

Fonte: IBGE, Censos Demográficos de 1980, 1991, 2000 e 2010 (dados da amostra).

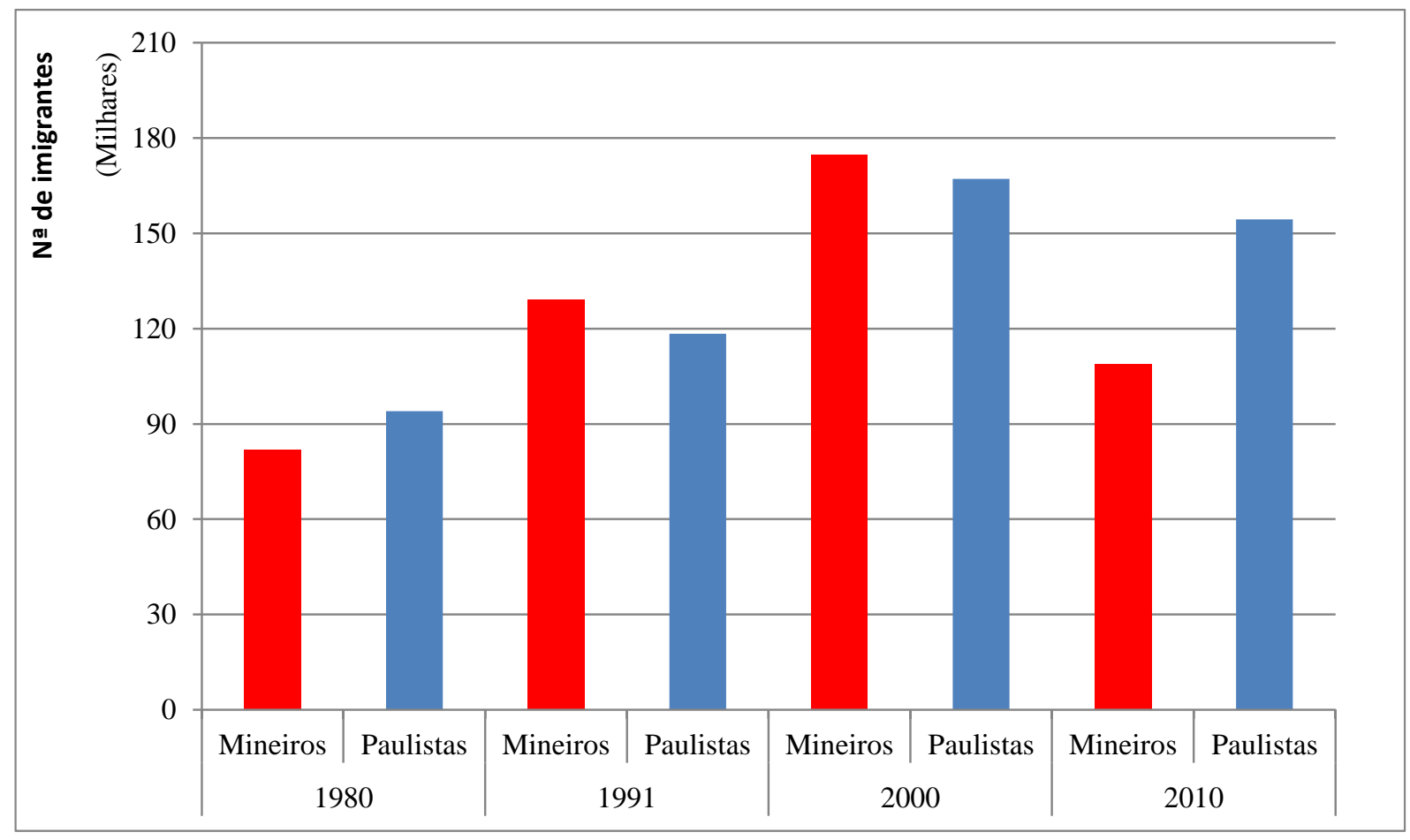

Figura 2: Imigrantes procedentes de São Paulo, residentes em Minas Gerais, conforme UF de nascimento (mineiros e paulistas), 1980, 1991, 2000 e 2010 - migração de última etapa Fonte: IBGE, Censos Demográficos de 1980, 1991, 2000 e 2010 (dados da amostra). 


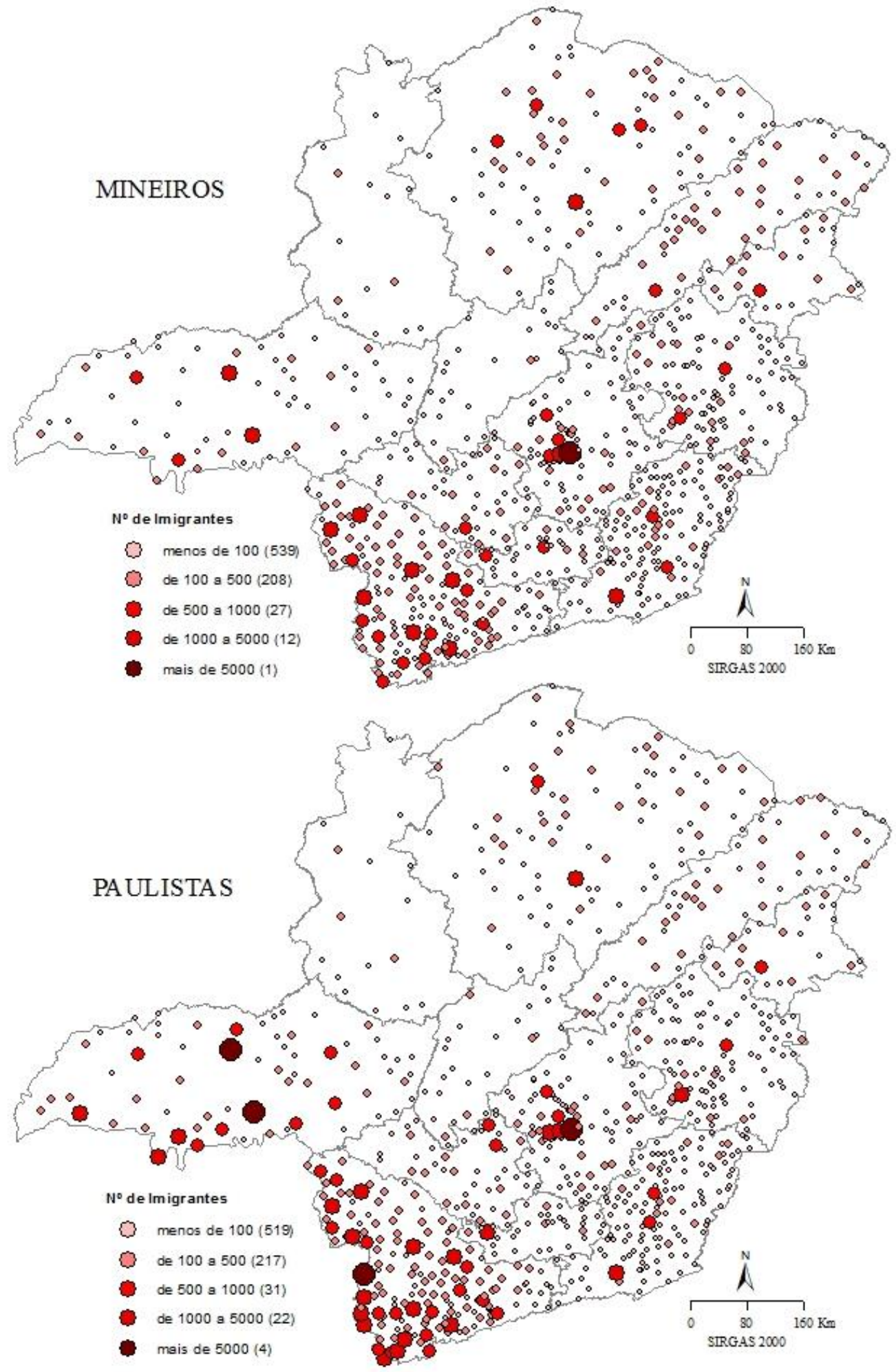

Figura 2: Imigrantes procedentes de São Paulo, residentes em Minas Gerais em 2010, conforme UF de nascimento (mineiros e paulistas), migração de última etapa

Fonte: IBGE, Censo Demográfico de 2010 (dados da amostra). 


\section{CONCLUSÕES E CONSIDERAÇÕES FINAIS}

Ainda que os fluxos migratórios interestaduais respondam pela saída de significativos contingentes de mineiros para São Paulo, bem como para outras regiões do Brasil, há indícios de novas tendências na dinâmica migratória regional, conforme sinalizam os dados do Censo Demográfico de 2000. De um estado eminentemente expulsor de população, Minas passou a receber crescentes contingentes migratórios, especialmente aqueles procedente do estado paulista. Nas trocas populacionais com São Paulo, identificadas pela migração de data fixa, as entradas têm sido bem relevantes. Além dos já conhecidos movimentos de espraiamento ao redor dos grandes pólos, como São Paulo, Rio de Janeiro, ou mesmo Belo Horizonte, novos centros urbanos têm se fortalecido regionalmente.

Em Minas, cidades de porte intermediário do Triângulo e Sul de Minas, como Uberlândia, Uberaba, Poços de Caldas, Pouso Alegre, Itajubá, Três Corações e Passos, por exemplo, têm se constituído em alternativa de fixação para migrantes procedentes de São Paulo. No entanto, além da migração de retorno, que tem mantido sua relevância no interior dos fluxos migratórios interestaduais, como já citado recorrentemente na literatura, também se destaca a migração de paulistas em direção a Minas, sobretudo para as regiões mais próximas a São Paulo. Essa forte presença de imigrantes paulistas em Minas, mesmo que concentrada em áreas geograficamente mais próximas, pode estar trazendo evidências acerca de um novo dinamismo regional.

Ainda que os resultados sejam restritos as últimas décadas, e necessitem de maior aprofundamento quanto as condições gerais que induzem o crescimento da imigração procedente do estado de São Paulo, algumas questões mais amplas merecem reflexão mais profunda: esses migrantes tem representado input relevante no capital humano regional? São mais qualificados e podem tem efeito indutor sobre o mercado de trabalho nos municípios receptores? Novas centralidades têm se consolidado nessas regiões receptoras? Essas, dentre outras, são questões que não devem ser ignoradas. Uma política de desenvolvimento regional deve, necessariamente, considerar os possíveis efeitos desse contingente migratório na dinâmica econômica regional. 


\section{REFERENCIAS BIBLIOGRÁFICAS}

AZZONI, C. Indústria e reversão da polarização no Brasil. Ensaios Econômicos, São Paulo, IPE/USP, n. 58, 1986.

BAENINGER, Rosana. Redistribuição espacial da população: características e tendências do caso brasileiro. Notas de população. Santiago do Chile, n. 65, p. 145/202, Jun. 1997. IBGE, Migração e deslocamento - Resultados da Amostra. Rio de Janeiro, 2003.

CARVALHO, J.; RIGOTTI, J. I. R. Os dados censitários brasileiros sobre migrações internas: algumas sugestões para análise. In: XI Encontro Nacional de Estudos Populacionais da ABEP, 1998.

DINIZ, C. C. Desenvolvimento poligonal no Brasil; nem desconcentração, nem contínua polarização. Nova Economia, Belo Horizonte, v. 31, n. 11, p. 35-64, set. 1993.

LOBO, C. Dispersão espacial da população no Brasil. Mercator, v. 15, n. 3, 2016

LOBO, C. Dispersão espacial da população nas Regiões de Influência das principais metrópoles brasileiras. Tese (Doutorado em Geografia), Instituto de Geociências, Universidade Federal de Minas Gerais, Belo Horizonte, 2009.

LOBO, C. et al. Expanded commuting in the metropolitan region of Belo Horizonte: evidence for reverse commuting. Revista Brasileira de Estudos Populacionais, 2015, vol.32, no.2, p.219233.

LOBO, C. e MATOS, R. Migrações e a dispersão espacial da população nas regiões de Influência das principais metrópoles Brasileiras. Revista Brasileira de Estudos Populacionais, 2011, vol.28, n.1, pp. 81-101.

LOBO, C. e MATOS, R. Dispersão espacial da população e do emprego formal nas regiões de influência do Brasil contemporâneo. Cadernos Metrópole, São Paulo, v. 12, n. 24, pp. 309-330, jul/dez 2010.

MARTINE, G. A redistribuição espacial da população brasileira durante a década de 80 . Brasília: Ipea, 1994.

MATOS, R. Questões teóricas acerca dos processos de concentração e desconcentração da população no espaço. Revista Brasileira de Estudos de População, São Paulo, p. 35-58, 1995. 
PACHECO, C. A. e PATARRA, N. Movimentos migratórios anos 80: novos padrões? In: PATARRA, N. (Org.). Migração, condições de vida e dinâmica urbana. Campinas: Unicamp, 1997, p. 25-72.

RAVENSTEIN, E. G. Leis da migração. In: MOURA, H. (Coord.). Migração interna: textos selecionados. Fortaleza: BNB, ETENE, 1980. p. 22-88.

RICHARDSON, H. W. Polarization reversal in developing countries. The Regional Science Association Papers. Los Angeles, v. 45, p. 67-85, Nov. 1980.

RIGOTTI, José I. R. Técnicas de mensuração das migrações, a partir de dados censitários: aplicação aos casos de Minas Gerais e São Paulo. Tese (Doutorado). Universidade Federal de Minas Gerais - CEDEPLAR. Belo Horizonte/MG, 1999.

RIGOTTI, J. I. R. Fluxos Migratórios e Distribuição Espacial da População na Região Metropolitana de Belo Horizonte na década de 70. 1994. 119f. Dissertação de Mestrado em Demografia - Universidade Federal de Minas Gerais - Centro de Desenvolvimento e Planejamento Regional, Belo Horizonte.

SANTOS, M. A natureza do espaço: técnica e tempo, razão e emoção. 2. ed. São Paulo:Hucitec, 1997.

SINGER, P. Economia política da urbanização. São Paulo: Hucitec, 1973.

TOWNROE, P.; KEEN, D. M. Polarization reversal in the state of São Paulo, Brazil. Journal of the Regional Studies Association. Cambridge, v. 18, n. 1, Feb. 1984. 